\title{
Conhecimento prévio de Paleontologia e Geologia de ingressantes em cursos de Ciências Biológicas e Geologia de universidades do Rio de Janeiro
}

Previous knowledge of Paleontology and Geology of recently enrolled students in Biological Sciences and Geology UNDERGRADUATE COURSES OF UNIVERSITIES OF RIO DE JANEIRO STATE

\author{
Sarah Gonçalves Duarte ${ }^{1,2,}$, Nayara de Macedo dos Santos ${ }^{3,5}$, Luana Graziella Bandeira ${ }^{4}$, Claudia Maria Magalhäes Ribeiro Martins ${ }^{3}$, Marcos Gervásio \\ Pereira ${ }^{2}$, Lúcio Carramillo Caetano ${ }^{3}$ \\ 1 - Secretaria de Estado de Educação Rio de Janeiro, RJ \\ 2 - Departamento de Solos, Universidade Federal Rural do Rio de Janeiro. Seropédica, RJ. \\ 3 - Departamento de Geociências, Universidade Federal Rural do Rio de Janeiro. Rio de Janeiro, RJ. \\ 4 - Secretaria Municipal de Educação de Angra dos Reis, Rio de Janeiro, RJ. \\ 5 - UneSP de RIO CLARO

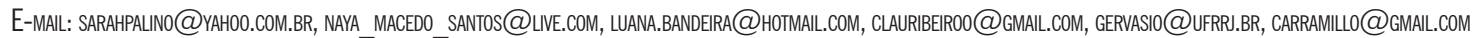

Abstract: The teaching of Paleontology and Geology is relevant, however, still Manuscrito: insufficiently and limitedly worked in basic education. Nowadays, education experts already affirm the importance of ascertaining the students' previous knowledge, including graduation, so that the process of teaching-learning it will be efficient. A research through a questionnaire was carried out to know about the previous knowledge of the students newly initiated in the courses of Biological Sciences and Geology of Rio de Janeiro, in relation to Paleontology and Geology. The results obtained pointed to problems in the teaching of these areas, because the students confused Paleontology with Archeology, have the concept of fossils limited to bones and do not have clear notions about the area of Geology, in general. This research is relevant as an alert to teachers of basic education about the importance of teaching geosciences in high school and fundamental and for undergraduate teachers to Recebido: 02/02/2019

Corrigido: 29/04/2019

Aceito: 02/09/2019

Citação: Duarte,S. G.; Macedo, N. M.; Bandeira, L. G.; Martins, C. M. M. R.; Pereira, M. G.; \& Caetano, L. C. (2019). Conhecimento prévio de Paleontologia e Geologia de ingressantes em cursos de Ciências Biológicas e Geologia de universidades do Rio de Janeiro. Terræ Didatica, 15, 1-12, e19032. doi: 10.20396/td.v15i0.8654529 worry about knowing the prior knowledge of studants to better refer them.

Palavras-chave: Ensino, Geociências, Graduação, Questionário, Conhecimento.

\section{A deficiência no ensino da Paleontologia e da Geologia no Ensino Básico no Estado do Rio de Janeiro}

O ensino da Paleontologia e da Geologia é de fundamental importância para a compreensão da história da vida e da formação do planeta Terra, pois permite um melhor entendimento da nossa própria origem e evolução. É de conhecimento, que essas ciências são pouco trabalhadas na Educação Básica como é discutido por Duarte et al. (2016), Sousa et al. (2016), Mendes et al. (2015), Izaguirry et al. (2013) dentre outros autores.

Duarte et al. (2016) publicaram o resultado de uma pesquisa apontando que $83 \%$ dos estudantes de ensino médio regular do Estado do Rio de Janeiro não sabiam o que era Paleontologia. Além disso, apesar de grande parte destes mesmos estudantes alegar já ter visto um fóssil (82\%), a maioria não sabia dizer o que era um fóssil, demonstrando a falta de conhecimento elementar em Paleontologia. Uma análise por meio de questionários feita por Mendes et al. em 2015 em uma escola em Porto Nacional no Tocantins também mostrou baixo desempenho por parte dos alunos nos temas relacionados à Paleontologia.

As razões de essas ciências serem pouco trabalhadas na educação básica são variadas tais como: inexistência ou pouca ênfase de conteúdos voltados para a Paleontologia e para a Geologia nos Currículos Mínimos das Secretarias de Estado de Educação do país (Teixeira, 2016), carência destes temas nos livros didáticos da educação básica (Compagnon et al., 2016), carga horária reduzida de Paleontologia nos cursos de formação de professores, pouca cobrança de temas relacionados com a Paleontologia e com a Geologia nos processos seletivos como concursos, vestibulares e uma má receptividade dos temas em ambientes educacionais devido à influência religiosa (Teixeira, 2016). Vale enfatizar 
também o limitado financiamento e investimento em projetos de extensão nas universidades voltados para a educação básica abordando a Geociências.

Em uma pesquisa onde os professores de ensino médio foram interrogados sobre o conceito de Paleontologia, as respostas dos mesmos mostraram o pouco domínio destes profissionais sobre o tema, apontando para uma formação de professores deficiente ou pouco atualizada (Sousa et al. 2016).

Outro problema adicional à falta de conhecimento em Paleontologia e Geologia dos estudantes e de professores formados é a carga horária reduzida destas disciplinas nos cursos de licenciatura, formando desta maneira uma geração de professores despreparados para trabalharem com os temas de Paleontologia e de Geologia em sala de aula de maneira adequada (Compagnon et al., 2016). Isso prejudica seriamente a propagação do ensino-aprendizagem das geociências como foi discutido por Duarte et al. (2018) e por Sousa et al. (2016).

Sendo assim, todos os problemas citados acima acarretam consequências nos estudantes que ingressam nas universidades no que diz respeito ao conhecimento sobre Paleontologia e Geologia.

\section{A importância do diagnóstico do conhecimento prévio dos estudantes recém ingressados na graduação}

Existe pouca preocupação ou interesse por parte dos professores universitários em saber sobre o conhecimento prévio dos seus estudantes da graduação em relação a sua disciplina. O que acontece na prática é apenas a confiança por parte dos professores no "conhecimento comprovado" pelo exame vestibular. Uma vez que o processo seletivo do vestibular é insuficiente para se ter um prognóstico ou uma ideia a respeito do que os estudantes trazem de conhecimento prévio, cabe aos professores avaliar estes conhecimentos dos estudantes através de questionários ou outras ferramentas de avaliação diagnóstica.

Esta prática facilitaria o processo de ensino-aprendizagem na medida que orientaria os professores na elaboração dos objetivos do aprendizado a partir do que os estudantes trazem ou não de conhecimento.

Esta prática também facilitaria na elaboração de aulas e na aplicação de técnicas de ensino apropriadas acompanhando o nível de conhecimento dos estudantes.
A referida problemática da falta do prognóstico é mais grave ainda com relação aos estudantes da graduação em licenciatura, pois estes deveriam já receber como exemplo de prática o prognóstico do conhecimento prévio das turmas por qualquer professor, para que no futuro estes estudantes da licenciatura (que serão futuros professores) realizem esta prática com seus alunos também.

\section{Objetivos}

Visando saber sobre o conhecimento prévio em Paleontologia e Geologia (Geociências) dos estudantes recém ingressados na graduação em Ciências biológicas e Geologia de instituições de ensino superior do estado do Rio de Janeiro, foi realizada uma análise através de "questionários" para averiguar o que estes estudantes traziam de conhecimentos sobre conceitos básicos de Paleontologia e Geologia, e a relação disto com a carência no ensino destas ciências durante a educação básica.

\section{Material e métodos}

A pesquisa foi realizada através de um "questionário diagnóstico misto" elaborado com dois tipos de questões: "questões fechadas", ou seja, com respostas que previamente eram esperadas que os estudantes respondessem de determinada maneira e "questões abertas", de respostas livres e subjetivas.

Este questionário foi respondido por estudantes universitários recém ingressados na graduação (primeiro período) de Ciências Biológicas da Universidade Federal Rural do Rio de Janeiro (UFRRJ), da Universidade Federal do Rio de Janeiro (UFRJ), da Universidade do Grande Rio (UNIGRANRIO), da Universidade Federal do Estado do Rio de Janeiro (UNIRIO), da Universidade Federal Fluminense (UFF), da Universidade do Estado do Rio de Janeiro (UERJ) e da graduação de Geologia da Universidade Federal Rural do Rio de Janeiro (UFRRJ).

O questionário foi passado em diversas universidades de diferentes áreas do Rio de Janeiro para que o trabalho tivesse uma maior abrangência e pluralidade, aumentando assim a representatividade da amostragem e da realidade educacional contextualizada com a localização (Figura 1).

O "questionário diagnóstico misto" foi elaborado com base em 7 (sete) questões (algumas com um subitem), que abordaram indagações relacionadas a Paleontologia e a Geologia. As questões 


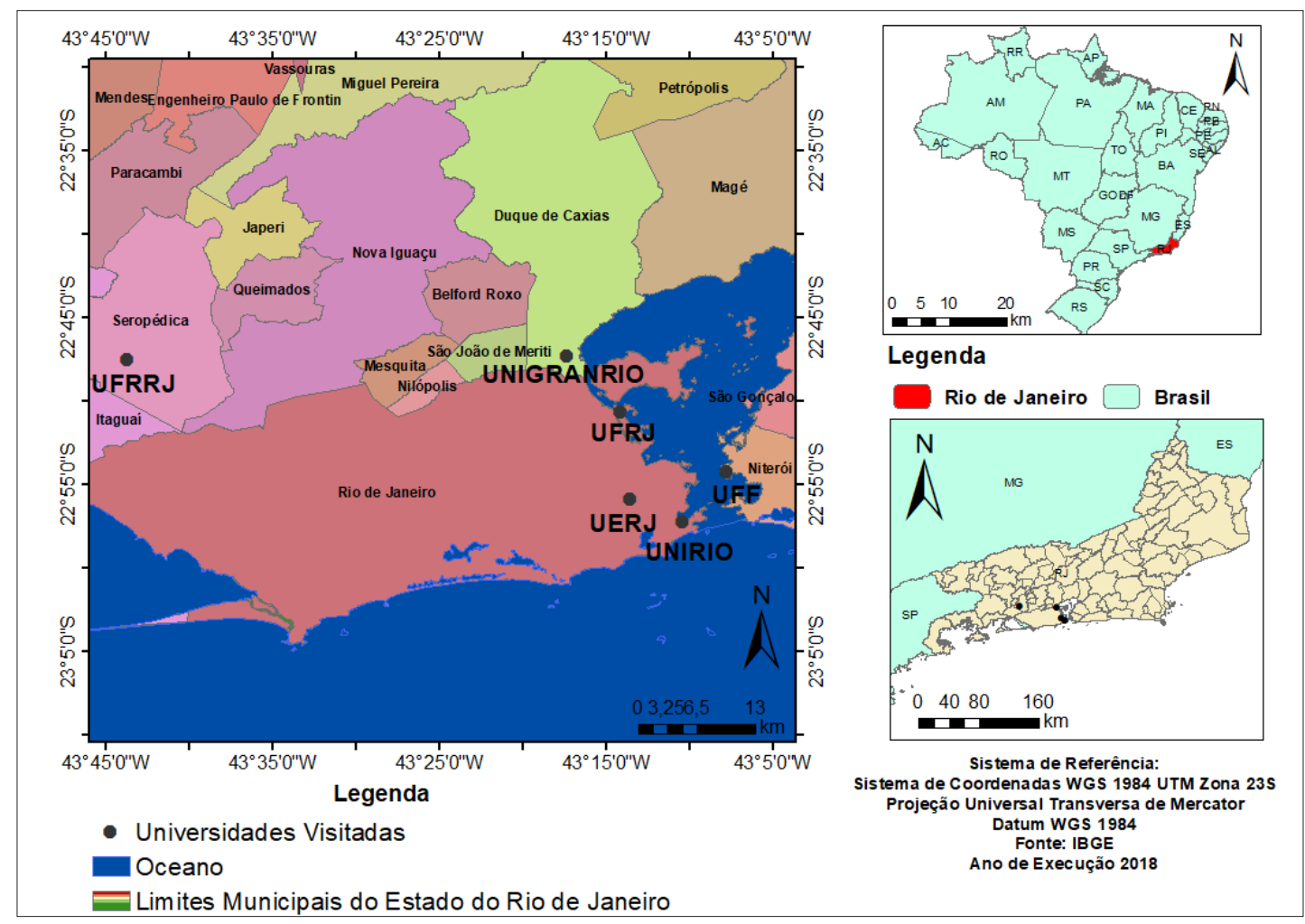

Figura 1. Mapa de localização das universidades pesquisadas no Estado do Rio de Janeiro

foram as seguintes:

1-Você tem noção do que estuda a Paleontologia?

2-Como você definiria Paleontologia?

3-Você sabe o que é um fóssil?

\section{1: Defina fóssil}

4- Você acha que a Paleontologia será importante para você na sua formação de biólogo/geólogo?

\section{1- Por que?}

5- Você tem noção do que estuda a Geologia?

6- Como você definiria Geologia?

7- Você acha que a Geologia será importante para você na sua formação de biólogo/geólogo?

\section{1 - Por que?}

Após os estudantes responderem, os questionários foram então avaliados pelos professores de Paleontologia e de Geologia envolvidos na pesquisa. A avaliação das "questões fechadas" foi realizada com base em um gabarito padrão do que se esperava como resposta para tais questões. Porém, existiam também algumas "questões abertas" (de cunho subjetivo), que não tinham um gabarito e estas foram analisadas individualmente sob o ponto de vista crítico dos avaliadores, mas não com a ideia de acertos e erros.

Após a avaliação de acordo com a análise das respostas, foram montadas planilhas com as contagens das respostas dos estudantes em cada questão e, posteriormente, gráficos foram confeccionados para uma melhor visualização e discussão dos resultados.

\section{Resultados}

No total, 195 estudantes responderam a este questionário diagnóstico misto. Na questão 1, que indagava sobre a noção do que estuda a Paleontologia, foi predominante a resposta que sabiam o que a Paleontologia estuda e menos de $10 \%$ afirmaram que não sabiam (sim: 177; não: 18) (Figura 2a).

Na questão 2, na qual foi solicitada a definição de Paleontologia, cerca de 73\% (143) deram uma resposta correta, o que foi surpreendente, e $10 \%$ (18) dos estudantes deram respostas incorretas. Os 17\% (34) restantes responderam parcialmente, porém, de maneira correta (Figura 2b).

Em relação à questão 3, mais de 90\% (179) dos estudantes responderam que sabiam o que era

\begin{tabular}{c|c|c|c|c|c|}
\hline (C) Terrae Didat. & Campinas, SP & v.15 & $1-12$ & $\mathrm{e} 019033$ & 2019 \\
\hline
\end{tabular}


um fóssil (Figura 2c), contudo quase 50\% (98) dos alunos definiram apenas parcialmente de maneira correta ou definiram incorretamente (Figura 2d).

Quanto à questão $4 \mathrm{em}$ que foi questionado aos estudantes se a Paleontologia seria importante para a formação dos mesmos em suas profissões de biólogos e geólogos, mais de 90\% (177) dos alunos responderam que achavam importante. Porém, menos de $10 \%$ (18), considerado uma minoria, afirmaram que não achavam importante (Figura 2e). E, ao serem questionados sobre a razão, ou seja, o porquê de acharem ou não a Paleontologia importante para a formação deles, 70 \% (137) dos alunos responderam que achavam que a Paleontologia era importante para as suas formações deram uma resposta coerente (Figura 2f).

$\mathrm{Na}$ questão 5, em que foi questionado se os estudantes sabiam o que estudava a Geologia, mais de $80 \%$ (160) dos estudantes recém ingressados no curso de Ciências biológicas responderam que sim (Figura 2g), porém menos de 40\% (71) dos alunos deram uma definição correta de Geologia na questão 6 , a qual solicitava uma definição desta ciência (Figura 2h). Em relação à questão 7 , mais da metade dos estudantes responderam que a Geologia seria importante para a formação deles, porém, surpreendemente, mais de 30\% (61) dos alunos responderam que a Geologia não seria importante para a sua formação (Figura 2i). E quando foi perguntada na questão 7.1 a razão destes estudantes terem respondido sim ou não sobre a importância da Geologia na formação deles, apenas 33\% (64) dos alunos escreveram uma resposta coerente (Figura 2j).

Um total de 195 alunos de graduação responderam a um questionário contendo as questões: a. Questão 1: Você tem noção do que estuda a Paleontologia? b. Questão 2: Como você definiria Paleontologia? c. Questão 3: Você sabe o que é um fóssil? d. Questão 3.1: Defina o que é um fóssil. e. Questão 4: Você acha que a Paleontologia será importante para você que pretende ser um Biólogo/ Geólogo? f. Questão 4.1: Por que? g. Questão 5: Você tem noção do que estuda a Geologia? h. Questão 6: Como você definiria Geologia? i. Questão 7: Você acha que a Geologia será importante para você que pretende ser um biólogo/geólogo? j. Questão 7.1: Por quê?

Algumas respostas dos estudantes entrevistados chamaram atenção quanto às conceituações e perspectivas equivocadas sobre a Paleontologia e sobre o estudo de Geociências.
A questão 1 que teve como objetivo averiguar a ideia geral que os alunos tinham com relação ao que estuda a Paleontologia, foi averiguada a limitação da ideia dos estudantes com relação a abrangência do estudo da Paleontologia como é comprovado abaixo com um exemplo:

Questão 1: Você tem noção do que estuda a Paleontologia?

Resposta 1Q1: "Sim, é o estudo de ossos" (apesar de dizer que tem noção do que estuda a Paleontologia, o estudante limita-se a dizer que esta ciência estuda apenas ossos e também não se refere a questão do tempo, que é relevante para considerar se uma estrutura é fóssil ou não).

Quando foi pedido ao aluno para que ele definisse Paleontologia, as repostas no geral demonstram que os estudantes confundem Paleontologia com Arqueologia e que muitos acham que a Paleontologia estuda apenas fósseis de animais. A seguir, alguns exemplos destas respostas:

Questão 2: Como você definiria Paleontologia?

Resposta 1Q2: "A busca de informações de sociedades e organismo muito antigos, ou extintos". (Notar que os estudantes costumam confundir Paleontologia com Arqueologia. Isso é percebido no trecho "informações de sociedades").

Resposta 2Q2: "Estudos dos artefatos e fóssil". (Notar que mais uma vez, a Paleontologia é confundida com Arqueologia. Isso é notado na palavra citada "artefatos").

Resposta 3Q2: "Estudo de restos mortais (ossos) de animais e animais antigos". (Notar que os estudantes focam apenas na existência de fósseis animais).

Resposta 4Q2: "Estudos de fósseis e coisas antigas". (Notar que foram citados fósseis, em geral, e não explicaram o que seriam as "coisas antigas").

Resposta 5Q2: "Estudo do passado da Terra e o seu desenvolvimento ao longo do tempo geológico". (Notar que não foram citados os organismos preservados, os fósseis, objeto de estudo da Paleontologia).

Resposta 6Q2: "Ciência que estuda os restos fósseis de vegetais e animais do passado." (Notar que aqui é citado não apenas os fósseis animais, mas 

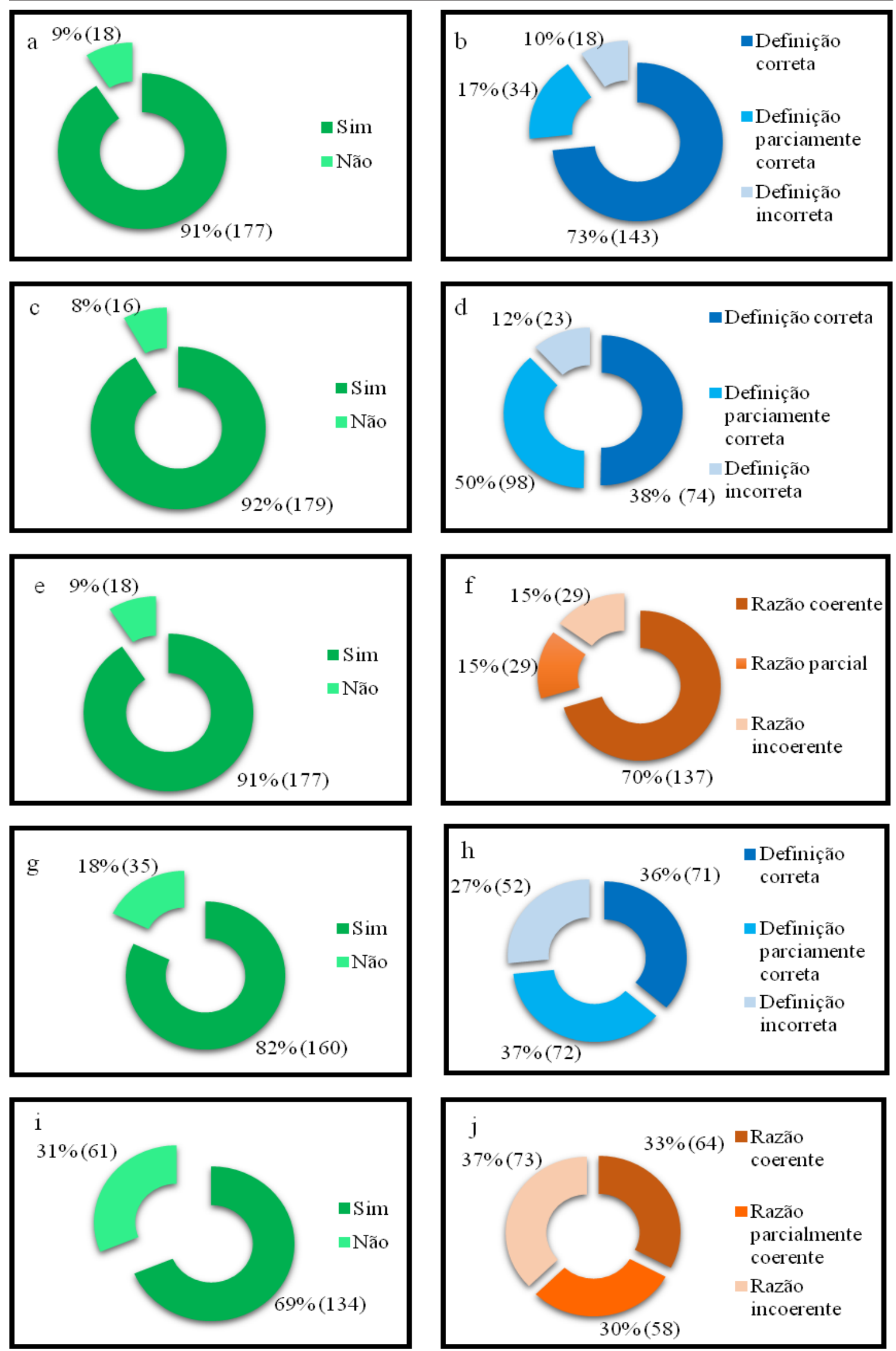

Figura 2. Gráficos com a porcentagem das respostas dos alunos às questões propostas (C) Terrae Didat. 
também os fósseis de vegetais, porém não são considerados outros grupos de organismos, como os fungos e os protozoários, que podem também ser preservados).

Resposta 7Q2: "Estuda os fósseis e formas de vida que ocorreram em um passado geológico". (Notar que a expressão "formas de vida" foi citada, embora devesse estar apenas citada como fóssil, já que foi colocada em termos de um passado geológico).

Quando os estudantes foram indagados sobre o que seria um fóssil, no geral os mesmos se limitam a referenciar restos ou vestígios de organismos ligados apenas aos animais e às plantas, não citando em momento algum a possiblidade de fossilização de outros grupos de organismos. Abaixo alguns exemplos:

Questão 3: Você sabe o que é um fóssil?

Resposta 1Q3: "Grosseiramente falando, ossos ou restos que estavam enterrados." (Notar que o estudante não cita a possiblidade da fossilização ocorrer em gelo, âmbar, rocha e não cita outras partes que podem ser preservadas como dentes, penas, folhas de plantas, sementes etc.)

Resposta 2Q3: “Fosseis são impressões deixadas no solo por restos de seres vivos, tanto animais quanto vegetais". (Notar que o estudante generaliza todos os processos de fossilização como "impressões" e não reconhece que outros organismos além de animais e plantas podem ser preservados).

Resposta 3Q3: "Sim, fóssil é uma estrutura que viveu há muitos anos, na pré-história. Embora saibamos que existem alguns fósseis vivos". (Notar que apareceu uma observação sobre fósseis vivos)

Resposta 4Q3: "Um fóssil é uma planta ou animal que vivia em outros períodos históricos o que ainda existe ou foi encontrado e estudado". (Provavelmente "o que ainda existe" seria uma outra referência a fóssil vivo).

Resposta 5Q3: "Algo bem antigo". (Notar que foi dada uma definição bem simplista e generalista);

Resposta 6Q3: "Sim, qualquer registro de vida antes do antropocêntrico". (Notar que o conhecimento sobre termos relacionados e tempo geológico foi falho).
Resposta 7Q3: "Sim, matéria orgânica e inorgânica de muitos anos". (Notar que o estudante usa o termo matéria e não vestígios ou partes de um ser vivo e nem estabelece um tempo geológico específico para ser considerado um fóssil).

Resposta 8Q3: "Sim, não sei definir". (Notar o desconhecimento sobre o assunto).

Resposta 9Q3: "Sim, acho, são organismos que viraram pedra”. (Notar que sabe, de modo geral, o conceito, porém, não aplicou corretamente o termo "rocha").

Resposta 10Q3: "Petrificação e solidificação de membros e corpos de seres vivos de qualquer espécie que já morreram". (Notar um conhecimento parcial sobre fósseis e processos de fossilização).

Resposta 11Q3: “Ossos”. (Notar que o estudante só reconhece "ossos" como fóssil).

Sabe-se que o estudo da Paleontologia é ferramenta fundamental para gerar dados que corroboram a teoria da evolução.

A evolução é disciplina de muita importância dentro da Biologia. Porém, ainda que a Paleontologia seja ferramenta da evolução, existe estudante que não a considera importante. Veja alguns exemplos de respostas a seguir de estudantes ao serem questionados sobre a importância da Paleontologia para a sua formação:

Questão 4: Você acha que a Paleontologia será importante para você que pretende ser um biólogo? 4.1 - Por que?

Resposta 1Q4: "Dependendo da área, sim. Hoje, não consigo perceber a importância para um professor de Biologia (ensino médio) ou professor de ciências (ginásio)". (Notar a gravidade do estudante não perceber a importância do ensino da Paleontologia na educação básica).

Resposta 2Q4: "Sim, porque através do estudo dos fósseis, teorias podem ser fundamentadas através de argumentos concretos". (Notar que o estudante não disse qual é a teoria, acreditamos que seja a da evolução).

Resposta 3Q4: “Sim, pois assim saberei identificar um animal". (Notar que o estudante considera a importância da Paleontologia mais relacionada com a taxonomia do que com a evolução). 
A Paleontologia também é área da Geologia. O desconhecimento da Paleontologia pode estar relacionado a falta de conhecimento sobre a Geologia. São poucos os estudantes do ensino médio que conhecem a carreira da Geologia. Abaixo isso é evidenciado com as respostas dos mesmos às questões 5 e 6 ao serem questionados sobre o que estuda a Geologia e como definiriam Geologia.

Questão 5: você tem noção do que estuda a Geologia?

Resposta 1Q5: “mais ou menos. " (Notar a resposta dada de forma indefinida, o que poderia levar a interpretação de que o aluno desconhece a importância desta ciência).

Resposta 2Q5: "Sim, estuda fenômenos ligados ao solo e como este sofreu alterações com o tempo e as erosões". (Notar que para este estudante a Geologia está apenas relacionada com a Pedologia).

Resposta 3Q5: "Sim, é o estudo do solo". (Nota-se que eles confundem a Geologia com Pedologia, matéria mais de formação de agronomia.).

Resposta 4Q5: "Sim, é o estudo do solo e de seus componentes". (Notar novamente que eles confundem a Geologia com a Pedologia, novamente).

Resposta 5Q5: "Não". (Notar que o estudante respondeu que não tinha noção do que estuda a Geologia, mas definiu, embora de modo bastante específico na questão 6 o que é a Geologia, afirmando que "é o estudo de rochas e minerais").

Resposta 6Q5: "Sim, estuda o meio em que vivemos (rochas, populações) e também política”. (Notar que, com esta definição, o estudante integra a Geologia com a Geografia).

Questão 6: Como você definiria Geologia?

Resposta 1Q6: "É o estudo das rochas préexistentes e dos minerais contidos nela." (Notar que, para o estudante, o conceito está associado exclusivamente as rochas).

Resposta 2Q6: "É o estudo de geografia física." (Notar que o estudante priorizou o conhecimento da Geografia para conceituar a Geologia.
Possivelmente, o mesmo deve estar se referindo tanto a "paisagem natural", como a "aspectos geomorfológicos", este último também relacionado à Geologia).

Resposta 3Q6: "É o estudo da formação da vida terrestre". (Notar que a resposta do estudante parece, em princípio, bastante equivocada. Porém, o mesmo deve ter tido alguma noção a respeito das explicações científicas sobre a origem da vida no planeta Terra. Provavelmente uma associação sobre a origem da vida nos mares "primitivos" durante o Arqueano, éon no qual o planeta Terra ainda estava em formação).

Resposta 4Q6: "É o estudo de um local". (Notar que o estudante provavelmente está referindo-se a "ambiente" e confundindo Geologia com Geografia; embora os ambientes paleontológicos e ambientes atuais estejam associados a estas duas áreas do conhecimento).

Quando os estudantes da Biologia foram questionados sobre a importância da Geologia na formação dos mesmos, ainda que não conhecessem bem Geologia, muitos consideraram que era importante saber Geologia para a uma boa formação do biólogo. Vide as respostas a seguir:

Questão 7: Você acha que a Geologia será importante para você que pretende ser um biólogo? 7.1- Por que?

Resposta 1Q7: Sim, por muitas espécies, por movimentação de placas tectônicas e eventos geológicos foram extintas e modificadas. [Notar que o estudante escreve um pouco desconexo, porém considera importante o estudo da Geologia para a sua formação como biólogo, pois percebe a integração por exemplo, do movimento das placas tectônicas (tema de estudo da Geologia) com processos de isolamento das espécies e evolução (tema de estudo da Biologia) ].

Resposta 2Q7: "Não, é uma ciência, na minha opinião, voltada para Geografia e não Biologia”. (Notar que o estudante não percebe a interação dos conhecimentos da Geologia com os da Biologia).

Resposta 3Q7: "Sim, pois os seres vivos estão diretamente ligados com o ambiente onde vivem, no caso dos terrestres, a terra, estudada pela Geologia”. (Notar que o 
estudante tem uma visão ecológica da interação dos fatores bióticos e abióticos, e provavelmente associa os fatores abióticos a Geologia)

Resposta 4Q7: "Sim, pois possibilita a previsão de possíveis eventos”. (Notar que o aluno não especifica os eventos e também não faz menção a nenhuma correlação de aspectos biológicos com os geológicos).

Resposta 5Q7: "Sim, porque também estuda a vida". (Notar que o estudante associa o estudo da vida com a Geologia. Talvez, o mesmo faça essa associação devido à Paleontologia também ser uma área da Geologia).

Resposta 6Q7: "Sim, para entendermos o local e conhecermos o local." (Notar que novamente o estudante não deixou claro o que seria "o local" e nem se estaria associado à Geologia ou à Geografia).

Resposta 7Q7: "Sim, localização. " (notar que poderá ser a mesma situação da resposta "6P7" e da mesma forma não especifica o significa "localização").

Resposta 8Q7: "Não sei ao certo. " (notar um desconhecimento do estudante em relação à interação da Geologia com a Biologia).

Resposta 9Q7: "Relativamente, como a geologia está envolvida com minerais que podem terem sido gerados por animais pode ser importante". (Notar uma resposta inexata e confusa por parte do estudante).

Resposta 10Q7: "Sim, porque na parte de ecologia da biologia o solo também é importante, principalmente na microbiologia. Já que o solo possui muitos micro-organismos importantes para a biologia". [Notar uma repetição de enfatizar a questão do "solo" (Pedologia) associado a Biologia].

Resposta 11Q7: "Sim, pois a Terra e a vida se movimentam em conjunto, se transformam em conjunto. Nem a Terra, nem a vida são estáticas". (Notar que esta seria uma das respostas mais coerentes e relacionadas ao conceito evolutivo, tanto da vida quanto do planeta Terra, como um todo).

Resposta 12Q7: “Sim, pois será possivel estabelecer relações entre determinados caracteres de uma espécie e a composição geológica do ambiente em que vive”.
(Notar um conhecimento sobre as relações entre os seres vivos e o ambiente).

De modo geral, as respostas não mostraram um desconhecimento total dos estudantes em relação à Paleontologia e às Geociências, porém, demonstraram falta de interesse e um conhecimento ainda insuficiente para estudantes que ingressaram para cursar a graduação em Ciências Biológicas e Geologia, cursos que exigem um conhecimento prévio ou mínimo sobre essas áreas do saber.

\section{Discussão}

\section{A importância de avaliar o conhecimento prévio dos alunos de Ciências biológicas e Geologia}

Atualmente é sabido que para uma boa concretização do processo de ensino- aprendizagem é extremamente importante o professor saber o conhecimento prévio de seus estudantes e problematizar este conhecimento (Santos, 2012). Assim é pregado hoje na educação básica e não deve ser diferente no nível superior.

O presente trabalho procurou saber o conhecimento prévio de alguns estudantes recém ingressados na graduação em Ciências Biológicas e em Geologia para que fosse feita uma reflexão e, desta forma, colaborar para um direcionamento na elaboração das aulas pelos professores.

Feijó \& Delizoicov (2016) afirmam que os professores têm dificuldades de saber sobre o conhecimento prévio dos estudantes e de problematizar esse conhecimento, gerando com isso lacunas na formação destes estudantes. Na medida que os professores desconhecem sobre o conhecimento prévio de seus estudantes, estes não irão elaborar aulas adequadas ao nível de conhecimento dos mesmos.

Ainda, segundo Feijó \& Delizoicov (2016), em cada momento histórico, as concepções de educação e ensino-aprendizagem orientam as práticas pedagógicas, visando a formação de sujeitos que atendam às demandas sociais. Hoje, por exemplo, segundo estes autores, existe a perspectiva de uma educação escolar que proporcione a formação de cidadãos autônomos, críticos, com capacidade de refletir sobre a própria realidade e contribuir para transformá-la.

E no nível superior, a formação deve proporcionar a reflexão e a formação de profissionais autônomos e críticos também. Para que isto ocorra, é necessário que os professores da graduação também 
busquem e compreendam o conhecimento prévio e os desejos dos seus estudantes para estabelecer melhores estratégias de ensino e encaminhá-los melhor em seu futuro profissional.

Há uma demanda crescente por educação superior e um reconhecimento sobre sua importância estratégica para o desenvolvimento econômico e social. Sem dúvida, a educação superior vem dando amplas demonstrações de sua importância para promover transformações na sociedade, por isso passou a fazer parte do rol de temas considerados prioritários e estratégicos para o futuro das nações (Neves, 2007).

Conhecer o que os estudantes, que vieram da educação básica, trazem de conhecimento sobre determinadas disciplinas e áreas do saber da universidade ao ingressarem no nível superior é extremamente importante. Pois isso, poderá colaborar com a elaboração de estratégias para a melhoria da educação superior, que está atualmente com uma demanda crescente. Além disso, fará com que seja observado e proposto o melhor caminho para preparar adequadamente os estudantes da educação básica para conhecerem melhor a graduação que pretendem cursar e as diversas áreas do saber desta graduação.

Sabe-se que para o estudante chegar mais preparado ao ensino superior, é extremamente importante interagir os conteúdos curriculares trabalhados com os mesmos nas escolas com o conhecimento produzido pela universidade, o que não parece estar sendo feito atualmente quando foram analisadas algumas respostas dos estudantes no presente trabalho.

Generaliza-se a convicção de que o desenvolvimento requer cada vez mais a ampliação dos níveis de escolaridade da população; e que as necessidades do desenvolvimento e consequentemente o novo perfil da demanda exigem flexibilidade, agilidade, alternativas de formação adequadas às expectativas de rápida inserção num sistema produtivo em constante mudança (Neves, 2007)

Devido aos cursos de graduação em Ciências biológicas e Geologia serem muito importantes para o desenvolvimento produtivo e científico do país, é relevante que os professores catedráticos destes cursos tenham noções do conhecimento prévio dos estudantes com relação à Paleontologia e à Geologia.
Ainda, segundo Neves (2007), a educação superior sofreu modificações ao longo das décadas e tornou-se mais flexível, e rompeu com padrões e modelos rígidos. Sendo assim, uma nova atuação e reflexão são necessárias por parte dos professores da graduação em relação ao método didático aplicado aos estudantes, buscando conhecer melhor a realidade do aprendizado anterior obtido pelos mesmos.

Silveira et al. (2014) demonstraram a importância de uma avaliação prévia para saber sobre o conhecimento trazido pelos estudantes da graduação com relação ao conteúdo de solos nos cursos de Zootecnia e Engenharia Hídrica da Universidade Federal de Pelotas, para que isto ajudasse aos docentes para um melhor direcionamento do seu método de ensino e encaminhassem corretamente os estudantes em suas formações. Segundo Lima (2005), o estudo do solo é importante devido a utilidade que este possui nas relações com o homem, servindo como fonte de alimentos e produção, estrutura básica para construções civis e ligação direta com a conservação ambiental.

No caso da Paleontologia, são relevantes o conhecimento e a compreensão sobre a origem e evolução da vida no planeta Terra, o que inclui, consequentemente, a origem e a evolução do homem. No que se refere à Geologia, é a compreensão da formação e estrutura do planeta Terra, das rochas, etc. Além disso, no caso da Geologia existe uma grande importância desta ciência em relação aos aspectos econômicos que qualquer estudante da educação básica deveria aprender como, por exemplo, a utilização dos minérios e suas aplicações.

É importante que a prática educacional seja realizada de forma exploratória e com acompanhamento diário do professor, sendo que a realização de diagnósticos iniciais e periódicos para traçar o perfil e observar o desenvolvimento da aprendizagem é de grande valor, seja na educação básica ou no nível superior (Silveira et al., 2014).

O acompanhamento auxilia a compreensão do estudante, permite o redirecionamento das rotinas e a identificação de falhas pontuais e ainda fomenta uma avaliação somativa, na qual todo o conhecimento agregado ao longo do período culmina em um resultado final (Marques \& Nasser, 2010).

Silveira et al. (2014) concluem que a aplicação de questionários e/ou outras formas de avaliação inicial do conhecimento é uma ferramenta importante que permite ao professor um melhor planejamento das atividades a serem realizadas, além de possibilitar que os conteúdos sejam abordados

\begin{tabular}{c|c|c|c|c|c}
\hline (C) Terrae Didat. & Campinas, SP & v.15 & $1-12$ & $\mathrm{e} 019033$ & 2019 \\
\hline
\end{tabular}


de forma mais prática e que se aproximem cada vez mais da realidade de cada curso e interesses profissionais dos estudantes, enfatizando métodos que chamem atenção e tragam uma maior aprendizagem.

Devido à problemática de várias áreas científicas, além da Paleontologia e da Geociências e de outros conhecimentos produzidos pelas universidades e instituições de pesquisas não chegarem até as escolas da educação básica ou chegarem lá de maneira equivocada, percebe-se a necessidade de uma maior aproximação entre a universidade e as escolas. Esta aproximação faz-se necessária por várias razões, dentre estas, melhorar o conteúdo trazido pelos estudantes recém ingressos nas universidades, pois muitos chegam despreparados em relação às informações elementares relativas à profissão que decidiram seguir. Isso é grave, pois muitas vezes o estudante poderá vir a escolher equivocadamente a profissão que pretende seguir devido à falta de conhecimento, o qual poderia ter sido levado pela universidade até a escola e ter chegado ao estudante.

A aproximação da universidade com a escola pode acontecer de diversas maneiras como através de projetos de extensão diversificados com ciclos de palestras, eventos, videoaulas na internet, curso de formação para professores, através da atuação de estagiários dentre outras maneiras.

Atualmente existe um programa do governo federal através do apoio da CAPES (Coordenação de Aperfeiçoamento de Pessoal de Nível Superior) denominado Programa Institucional de Bolsas de Iniciação à Docência-PIBID, que visa aproximar mais a universidade da educação básica a partir do pagamento de bolsas a estudantes da licenciatura que fazem estágios em escolas. Com este tipo de programa, estudantes da licenciatura em Ciências Biológicas e de outros cursos podem levar conhecimento sobre temas relacionados com a Paleontologia e a Geologia, durante seus estágios nas escolas, por intermédio de diversas atividades a serem trabalhadas com os estudantes da educação básica.

O programa acima citado, se bem estruturado e desenvolvido, promove uma boa integração entre o ensino superior e a educação básica, como exemplificado no trabalho de Tavares (2015).

\section{Discussão sobre as respostas dos alunos}

Quando um aluno chega à universidade oriundo da educação básica, traz consigo vários conte- údos aprendidos e experiências pessoais. Muitos alunos têm apenas o ensino médio convencional; alguns têm o ensino médio técnico; outros pararam de estudar, foram trabalhar e depois optaram por fazer uma graduação, ou seja, cada um tem a sua história, sua realidade.

Sendo assim, ao responderem ao questionário aplicado, cada um mostrou o seu "conhecimento" de acordo com a sua realidade educacional anterior. Ao analisar as respostas do questionário com relação a questão 1- Você tem noção do que estuda a Paleontologia? Observou-se que alguns alunos tiveram um contato maior com a Paleontologia no ensino básico e outros não. Uma das respostas foi "Sim, é o estudo de ossos" e uma outra foi "Estuda os fósseis e formas de vida que ocorreram em um passado geológico". A segunda resposta claramente demonstra um conhecimento mais profundo e maior contato do aluno com a Geociências do que o aluno que deu a primeira resposta.

Com relação a "Questão 2: Como você definiria Paleontologia?", a resposta "A busca de informações de sociedades e organismos muitos antigos, ou extintos", enfatizando um desconhecimento sobre a diferença entre Paleontologia e Arqueologia, no que tange aos conceitos e objetos de estudo.

Nesta outra resposta com relação a definição da Paleontologia "Estudo de restos mortais (ossos) de animais e animais antigos", observa-se o desconhecimento com relação a fósseis de organismos que não sejam de animais, demonstrando o reflexo da carência no ensino da Paleontologia e até mesmo da Botânica também na educação básica.

Fazendo uma comparação das respostas com relação as perguntas que envolvem "o que seja a Paleontologia" e a "definição de fósseis", observa-se que neste trabalho e no trabalho de Duarte et al. (2016) foram registradas respostas que limitam a definição de fósseis como ossos enterrados ou como animais.

Quando um aluno responde à questão 5 em que é questionado sobre se ele sabe o que estuda a Geologia e este responde "Sim, estuda fenômenos ligados ao solo e como este sofreu alterações com o tempo $e$ as erosões "claramente observa-se que este aluno provavelmente teve contato com a área da Pedologia, seja na escola convencional ou técnica, e este conhecimento deve ser levado em conta pelos professores da graduação para direcioná-lo ao adequado aprendizado do ensino ligado à Geologia.

Vale ressaltar que em muitas respostas acerca das questões que abordavam a Geologia, os alunos 
não apresentaram segurança ao respondê-las. Muitos disseram saber o que era Geologia, mas em suas definições notou-se que esses alunos não tinham o entendimento suficiente sobre o que era essa área, enquanto que, para aqueles alunos que disseram não saber, suas definições estavam coerentes. Algumas respostas demonstraram claramente que os alunos confundiram Geologia com Geografia e, em alguns casos, definiram esta área como sendo "medicina do solo", muito embora a Geologia tenha em seu conteúdo disciplinar o conhecimento sobre noções básicas do que é "solo", sendo este assunto abordado de modo mais amplo e específico no curso de Engenharia Agronômica.

O mais alarmante foi uma parcela considerável de alunos que cursavam Geologia não saberem definir a mesma, e a grande maioria dos estudantes, tanto da Geologia, como das Ciências Biológicas, não terem um conhecimento mínimo sobre esta ciência e da sua importância para a sociedade.

Duarte et al. (2016) publicaram um trabalho intitulado "Paleontologia no Ensino Básico das Escolas da Rede Estadual do Rio de Janeiro: uma Avaliação Crítica”. Neste trabalho foi passado um questionário um pouco semelhante ao do presente trabalho, em diferentes escolas do estado do Rio de Janeiro, e foi observado um melhor desempenho dos alunos que estudavam em bairros próximos a universidades ou que tinham contato com projetos de extensão de alguma universidade. Isto demonstrou a importância da interação "escola e universidade" para a formação do aluno, para a sua escolha de carreira e conhecimento da Geociências.

\section{Conclusões}

Com este resultado, foi notável que mesmo com problemas no ensino da Paleontologia e da Geologia na educação básica, a maioria dos estudantes chegaram à graduação tendo uma noção prévia sobre Paleontologia, ainda que esta noção fosse incompleta. $\mathrm{O}$ mesmo não ocorreu em relação ao conhecimento sobre Geologia, até mesmo para quem era recém-ingressado na graduação em Geologia, pois apesar da maioria ter respondido que tinha noção do que estudava a Geologia, uma minoria conseguiu defini-la corretamente.

Os estudantes de ambas as graduações (Ciências biológicas e Geologia), em sua maioria, assumem que a Geologia tem importância para a sociedade, mas apenas uma pequena parcela, sabe quais são as reais aplicabilidades dessa área do saber.
Essa pesquisa foi relevante para fazer um alerta aos professores sobre a importância do ensino das Geociências durante a educação básica para que os estudantes não cheguem ao nível superior com carências e deficiências. É extremamente importante o professor de cursos de graduação conhecer o que os seus alunos trazem de conhecimento para que ele elabore aulas mais direcionadas à realidade deles e para que os encaminhe melhor a um conhecimento geral e especifico sobre vários aspectos da Paleontologia e da Geologia.

Conclui-se também que a aproximação da escola com a universidade tem um papel fundamental no encaminhamento do aluno, para que o mesmo tenha um melhor aproveitamento e aprendizado do que é ensinado na universidade. Porém, esta aproximação deve ocorrer de forma integrada com as diversas áreas do saber, de forma que haja uma interação entre as disciplinas e uma construção de conhecimento mais sólida e bem estruturada, ao invés do perfil fragmentado das grades disciplinares, observado nos cursos de graduação.

\section{Agradecimentos}

Nosso agradecimento aos departamentos associados aos cursos de Ciências Biológicas e Geologia da UFRRJ, UFRJ, UNIGRANRIO, UNIRIO, UFF e UERJ, por terem permitido a realização dessa avaliação diagnóstica.

Da mesma forma, os autores agradecem à bióloga Simone Senra Lessa e ao geólogo José Eduardo Giannini Esteves, por terem ajudado a distribuir os questionários nas universidades.

\section{Referências}

Compagnon, J. M.; Maciel, E. S.; Cidade, M. P.; Melo, R. M.; Costa, E. R.; \& Feltran, R. B. (2016). Ciência alimentando o Brasil A Paleontologia no processo de Ensino Aprendizagem dos alunos do $7^{\circ}$ Ano da sede do município de Boa Vista, Roraima. In: XI Semana Nacional de Ciência e Tecnologia no Estado de Roraima, SNCT-RR, 11. Anais... Roraima URL: https://even3storage.blob.core.windows.net/ anais/36019.pdf. Acesso 16.12.2018.

Duarte, S. G.; Arai, M.; Passos, N. Z. G., \& Dolores, M. W. (2016). Paleontologia no ensino básico das escolas da rede estadual do Rio de Janeiro: uma avaliação crítica. Anuário do Instituto de Geociências da UFRJ 39(2), 124-132. [https://doi. org/10.11137/2016_2_124_132]

Duarte, S. G.; Martins, C. M. M. R., Bandeira, L. G., 
Carramillo, L. C., Gervásio, C. M., \& Wanderley, M. D. (2018). Experiência interdisciplinar na educação básica e na formação de professores: Artes, Biologia e Geociências. Terrce Didatica 14(3), 245-255. doi: https://doi.org/10.20396/td. v14i3.8652424.

Feijó, N.; \& Delizoicov, N. C. (2016). Professores da educação básica: conhecimento prévio e problematização. Revista Retratos da Escola, 10(19), 597610. doi: 10.22420/rde. v10i19.643.

Lima, M.R. (2005). O solo no ensino de ciências no nível fundamental. Ciência \& Educação 11(3), 383394. doi: 10.1590/S1516-73132005000300004.

Izaguirry, B. B. D.; Ziemann, D. R.; Muller, R. T.; Dockhorn, J.; Pivotto, O.L.; Costa, F.M.; Alves, B.S.; Ilha, A. L. R.; Stefenon, V. M.; \& da Silva S.D. (2013). A paleontologia na escola: uma proposta lúdica e pedagógica em escolas do município de São Gabriel, RS. Cadernos da Pedagogia, 7(13), 2-16.

Marques, E. O.; \& Nasser, L. (2010). Planejamento de atividades didáticas a partir dos resultados de avaliações em larga escala. In: Encontro Nacional de Educação em Matemática no Estado da Bahia 11. Anais.... Bahia URL: http://www.pg.im.ufrj.br/pemat/03\%20Elizabeth\%20Ogliari.pdf. Acesso 13.12.2018.

Mendes, L. A. S.; Nunes, D. F.; \& Pires, E. F. (2015). Avaliação do conhecimento paleontológico com intervenção em escolas de ensino médio: um estudo de caso no Estado do Tocantins. Holos 31(8), 384-396. Doi: https://doi.org/10.15628/holos.2015.1991.

Neves, C. E. B. (2007). Desafios da educação superior. Sociologias 9 (17), 14-21.
Santos, L. P. (2012). A relação da Geografia e o conhecimento cotidiano vivido no Lugar. Geografia Ensino E Pesquisa 16 (3), 107-122.

Silveira, C.P.L.; Dubow, M.; Souza, M. F.; Milani, I. C. B.; \& Suzuki, L. E. A. S. (2014). Conhecimento prévio de estudantes do ensino superior para a educação em solos. In: Reunião Sul-Brasileira de Ciência do Solo Fatos e Mitos em Ciência do Solo no Estado do Rio Grande do Sul 10. Anais... Rio Grande do Sul. URL: https://wp.ufpel.edu.br/rhima/files/2010/09/ trab-9-3238-175-Caroline-Educação.pdf. Acesso 13.12.2018.

Sousa R.C.; da Silva I.R.; Santos S.F. dos; de Figueiredo A.E.Q.; \& Fortier D. C. (2016). O ensino de Paleontologia nas escolas públicas estaduais de Floriano-PI na concepção dos docentes. In: III Congresso Nacional de Educação no Estado do Rio Grande do Norte. Anais... Rio Grande do Norte URL: http://www.editorarealize.com.br/revistas/conedu/ trabalhos/TRABALHO_EV056_MD4_SA18_ ID10955_17082016193329-pdf. Acesso 05.05.2018.

Tavares R. F. O. (2015). Integração da Educação Superior à Educação Básica: Uma experiência do PIBID no Ensino Médio. Fronteiras: Journal of Social, Technological and Environmental Science, 4(3), 231237. doi: 10.21664/2238-8869.2015v4i3.p231-237.

Teixeira P. P.(2016). Ensino de evolução e religiosidade: o caso de duas escolas estaduais do Rio de Janeiro. Rio de Janeiro (Tese de Doutorado). Departamento de Educação, Pontifícia Universidade Católica do Rio de Janeiro. URL: https://www.maxwell.vrac. puc-rio.br/27465/27465.PDF. Acesso 16.12.2018. 